\title{
Pre-morbid intelligence, the metabolic syndrome and mortality: the Vietnam Experience Study
}

\author{
G. D. Batty • C. R. Gale • L. H. Mortensen • \\ C. Langenberg • M. J. Shipley $•$ I. J. Deary
}

Received: 17 October 2007 / Accepted: 23 November 2007 / Published online: 18 January 2008

(C) Springer-Verlag 2007

\begin{abstract}
Aims/hypothesis We examined the relationship between pre-morbid intelligence quotient (IQ) and the metabolic syndrome, and assessed the role of the metabolic syndrome as a mediating factor in the association of IQ with total and cardiovascular disease (CVD) mortality.

Methods In this cohort study, 4,157 men with IQ test results from late adolescence or early adulthood [mean age
\end{abstract}

G. D. Batty $(\bowtie)$

MRC Social and Public Health Sciences Unit,

University of Glasgow,

4 Lilybank Gardens,

Glasgow G12 8RZ, UK

e-mail: david-b@sphsu.mrc.ac.uk

G. D. Batty $\cdot$ I. J. Deary

Department of Psychology, University of Edinburgh,

Edinburgh, UK

C. R. Gale

MRC Epidemiology Resource Centre,

University of Southampton,

Southampton, UK

L. H. Mortensen

National Institute of Public Health,

Copenhagen, Denmark

C. Langenberg

MRC Epidemiology Unit,

Cambridge, UK

M. J. Shipley

Department of Epidemiology and Public Health,

University College London,

London, UK (range) 20.4 (16-30) years] attended a clinical examination in middle-age [38.3 (31-46) years] at which the components of the metabolic syndrome were measured. They were then followed for 15 years to assess mortality.

Results In age-adjusted analyses, IQ was significantly inversely related to four of the five individual components comprising the metabolic syndrome: hypertension, high BMI, high triglycerides and high blood glucose, but not low HDLcholesterol. After controlling for a range of covariates that included socioeconomic position, higher IQ scores were associated with a reduced prevalence of the metabolic syndrome itself (odds ratio 1 SD increase in IQ $0.87,95 \% \mathrm{CI}$ 0.78-0.98). Structural equation modelling revealed that education was not a mediator of the relationship between IQ and the metabolic syndrome. The metabolic syndrome partially mediated the relationship between IQ and CVD but not that between IQ and total mortality.

Conclusions/interpretation In this cohort, higher scores on a pre-morbid IQ test were associated with a lower prevalence of the metabolic syndrome and most of its components. The metabolic syndrome was a mediating variable in the IQ-CVD relationship.

Keywords Cardiovascular disease $\cdot$ CVD . Intelligence quotient · IQ · Metabolic syndrome .

Mortality $\cdot$ Socioeconomic position

$\begin{array}{ll}\text { Abbreviations } \\ \text { CVD } & \text { cardiovascular disease } \\ \text { HR } & \text { hazard ratio } \\ \text { IQ } & \text { intelligence quotient } \\ \text { OR } & \text { odds ratio } \\ \text { PCA } & \text { principal components analysis }\end{array}$




\section{Introduction}

Empirical research in the field of cognition (i.e. intelligence quotient, IQ), has a long tradition in the social sciences. It has recently been suggested that the skills captured by IQ tests, such as comprehension and reasoning, may have a role in an individual's interpretation of health promotion advice and hence their choice of behaviours [1]. Thus, in comparison to their lower-performing counterparts, higher IQ-scoring individuals have more favourable levels of cigarette smoking [2-5] (uptake and cessation), physical activity [6] and dietary characteristics [6, 7]. Although there are fewer studies exploring the link between IQ and physiological variables, it has been suggested that higher IQ scores are associated with lower levels of blood pressure or hypertension [3, 8,9] and obesity [10-12]. The scant reports of the relationship between IQ and later measurement of serum cholesterol and high blood glucose or diabetes [13] reveal null results, although sample sizes are modest. While some of these risk indices represent the cluster of factors comprising the metabolic syndrome, to our knowledge, the relationship between IQ and this constellation of risk indices has not been examined.

Data from the Vietnam Experience Study, a large cohort of former US army personnel who had their IQ assessed at entry to the service in early adulthood and then took part in a telephone interview and medical examination some 20 years later [14-16], provide a novel opportunity to examine the IQ-metabolic syndrome relationship. As the vital status of these men post-medical examination is also known, an additional novel objective of the present analyses is to examine the mediating role, if any, of the metabolic syndrome in the association between IQ and both total and cardiovascular disease (CVD) mortality.

\section{Methods}

Data collection in late adolescence or early adulthood Study participants were identified retrospectively using existing military records, a process that has been described in detail elsewhere [14-16]. In brief, information pertaining to place of service, military rank, ethnicity and IQ were extracted from military archives for 18,313 former military personnel.

On enlistment into military service, the men routinely completed a general aptitude (IQ) test: the Army General Technical Test. This consists of two subtests, verbal and arithmetic reasoning. We validated this test by comparing scores from it with those from components of the Wechsler Adult Intelligence Scale, a comprehensive and widely used test of cognitive ability that study participants $(n=4,411)$ completed during the medical examination in middle-age (described below). Total Army General Technical Test results were strongly correlated with information subtest scores $(r=0.74,95 \%$ CI $0.73-0.76)$, block design scores $(r=0.51,95 \%$ CI $0.49-0.55)$ and overall results $(r=0.74$, $95 \%$ CI $0.73-0.76$ ) from the Wechsler Adult Intelligence Scale. Mean age at army entry when IQ was assessed was 20.4 years (range $16-30$ ).

Data collection in middle-age - telephone survey A total of 15,288 (85.6\% of target population) of 17,867 men found to be alive on 31 December 1983 participated in the 1985 telephone survey, during which enquiries were made about the study participants' medical history, health behaviours and socioeconomic characteristics. Socioeconomic position was measured using household income, an index of occupational prestige $[17,18]$ and years of completed education.

Data collection in middle-age-medical examination In 1986, a random sample of telephone interview respondents $(n=6,443)$ was invited to attend a 3 day medical examination; 4,462 attended (69.3\% of those invited; mean age 38.3 years, range $31-46$ ). All men were requested to fast from 19:00 hours on the evening before medical testing. Blood was drawn the following morning and levels of triglycerides and cholesterol fractions ascertained using an autoanalyser (Ektachem 700; Kodak, Rochester, NY, USA) $[19,20]$. Serum glucose level was determined with a standard adaptation of the glucose oxidase-peroxidasechromogen-coupled system for glucose determination in biological fluids $[19,20]$. Blood pressure, height and weight were assessed using standard protocols. Body mass index was computed using the usual formula (weight $[\mathrm{kg}] /$ height $[\mathrm{m}]^{2}$ ). Subsequent to completion of the medical examination, attempts were made to match study participants against mortality databases for a 15 year period.

Definition of the metabolic syndrome We used two methods to define the metabolic syndrome. In the first method, we defined the metabolic syndrome and its components using a modified version of the Adult Treatment Panel III recommended diagnostic criteria [21] (here, termed the conventionally derived index). According to this definition, participants were classified as having the metabolic syndrome if any three of the following were present: BMI $>30 \mathrm{~kg} / \mathrm{m}^{2}$ (in the absence of data on waist circumference, BMI at this threshold is regarded by the WHO as an acceptable substitute in defining the metabolic syndrome [22]); fasting plasma glucose $\geq 6.1 \mathrm{mmol} / 1(110 \mathrm{mg} / \mathrm{dl})$ or medication for diabetes (as reported at the medical examination); triglycerides $\geq 1.7 \mathrm{mmol} / 1 \quad(150 \mathrm{mg} / \mathrm{dl})$; HDL-cholesterol level $<1.036 \mathrm{mmol} / \mathrm{l}(40 \mathrm{mg} / \mathrm{dl})$; and blood pressure $\geq 130 / 85 \mathrm{mmHg}$ and/or use of antihyperten- 
sive medication. A second approach was based on evidence that a single latent factor may underlie the core components of the metabolic syndrome [23]. We therefore carried out a principal components analysis (PCA) of BMI, triglycerides, HDL, blood glucose, systolic and diastolic blood pressure, and use of antihypertensive medication. To ascertain whether a single underlying component was sufficient to describe the associations among these variables, we used the scree slope criterion [24]. The scree slope showed just one substantial component above the 'scree' of trivial components and we therefore extracted a single score based on the first unrotated principal component (here, termed the PCA-derived index).

Statistical analysis The present analyses are based on a sample of men with complete information on IQ, covariates obtained at entry into the army, telephone interview and medical examination, and mortality $(n=4,157)$. This group represents $23.3 \%$ of persons originally enrolled in the study. Although this analytical sample is based on the recruitment of a random sample of surviving men, concerns about selection bias are nonetheless possible; that is, if the reported results differ markedly between persons included in the analyses and those not. In Table 1 we present the early adult characteristics of men in the analytical cohort with those of men excluded from the sample. Differences were very small: in comparison to the excluded group, men

Table 1 Comparison of early adult characteristics of men included in the analytical sample with those excluded

\begin{tabular}{llll}
\hline & $\begin{array}{l}\text { Included } \\
(n=4,157)\end{array}$ & $\begin{array}{l}\text { Excluded } \\
(n=11,131)\end{array}$ & $p$ value \\
\hline $\begin{array}{llll}\text { Army income } \\
\text { (US\$ per week) }\end{array}$ & $513(12.3)$ & $1,395(12.5)$ & 0.94 \\
$83-119$ & $2,059(49.5)$ & $5,486(49.3)$ & \\
$120-144$ & $1,585(38.1)$ & $4,250(38.2)$ & \\
145 & & & \\
Place of service & $2,299(55.3)$ & $5,625(50.5)$ & $<0.001$ \\
Ever served in Vietnam & $1,069(25.7)$ & $3,179(28.6)$ & \\
$\begin{array}{l}\text { Other overseas posting } \\
\text { Served in USA only }\end{array}$ & $789(19.0)$ & $2,327(20.9)$ & \\
Ethnic group & $3,405(81.9)$ & $9,228(82.9)$ & 0.21 \\
$\quad$ White & $492(11.8)$ & $1,203(10.8)$ & \\
$\quad \begin{array}{llll}\text { Black } \\
\text { Other }\end{array}$ & $261(6.3)$ & $700(6.3)$ & \\
IQ at enlistment, & $101.3(15.2)$ & $100.4(14.9)$ & 0.001 \\
mean (SD) & & & \\
Age at enlistment (years), & $19.9(1.72)$ & $19.9(1.70)$ & 0.67 \\
mean (SD) & & & \\
\hline
\end{tabular}

Values are $n(\%)$, unless otherwise indicated

${ }^{a}$ Comprises Hispanics, Asians, Pacific Islanders, American Indians and Alaskan Natives in the analytical sample had higher IQ test scores and a greater proportion with service experience in Vietnam. The fact that these marginal differences reached statistical significance can be ascribed to the large sample size.

We assessed the relationship between IQ and the metabolic syndrome in three ways that provided complementary information. In the first analyses, we used logistic regression to examine the relationship between IQ and both each individual component of the metabolic syndrome and the conventionally derived metabolic syndrome. In these analyses, outcomes were dichotomised and adjustments were made for a range of covariates (age, rank, ethnicity, education, income and social prestige). In the second analyses, by computing Pearson partial correlation coefficients, we related IQ to the naturally coded (continuous) versions of the components of the metabolic syndrome and the PCA-derived index described above, which represents a score for the metabolic syndrome. This preserves all the information in the variables and provides effect sizes for associations. Third, we carried out an analysis using structural equation modelling with the EQS program, version 6.1 [25]. In the hypothetical model, a latent trait of general cognitive ability was formed from the verbal and arithmetic ability test scores. The following indicators were used to form a latent trait of metabolic syndrome: systolic blood pressure, BMI, triglycerides, HDL-cholesterol, glucose and hypertensive medications. The explicit hypothesis tested was that latent general mental ability influenced the latent metabolic syndrome trait and that some of that effect was mediated via education, a close correlate of IQ [26]. The measurement models (for the latent traits) and the structural model (the path part of the model) are given in Fig. 1. The fit of the model was tested comprehensively, as described in the results section.

Finally, to examine the mediating role of the metabolic syndrome, if any, between IQ and mortality from all causes and CVD we computed hazard ratios (HRs) and accompanying 95\% CIs using Cox proportional hazards regression model with age as the underlying time scale [27]. IQ was used as a continuous measure with effect estimates reported for a $1 \mathrm{SD}$ increase. Follow-up time was taken from the medical examination until censoring, death or 31 December 2000, whichever came first (mean follow-up time 15.1 years).

The Vietnam Experience Study was authorised by the US Congress. The protocol for the study was reviewed by the US Office for Technology Assessment, the Department of Health and Human Sciences Advisory Committee, the Agent Orange Working Group Science Panel and a panel from the US Centers for Disease Control. On the first day of the medical examination, participants attended an orientation session and signed a consent form. 


\section{Results}

In Table 2 we present the relationships between IQ and study covariates. IQ was associated with each of the indicators of socioeconomic position during service (army income) and in middle-age (income, occupational prestige and education), such that there was a lower level of disadvantage in the groups with higher IQ scores. Higher IQ scores were also apparent in veterans who were white and in those whose place of service did not include Vietnam.

Table 3 depicts the relationship between IQ, components of the metabolic syndrome and the metabolic syndrome itself. In age-adjusted analyses, with the exception of HDLcholesterol, all components of the metabolic syndrome in middle-age were inversely related to IQ in early adulthood at conventional levels of statistical significance. Controlling for ethnicity led to partial attenuation of the inverse associations of IQ with hypertension and blood glucose, and accentuated the triglycerides association, but had little effect on the other metabolic components. With the exception of triglycerides as an endpoint, separate adjustment for adult indices of socioeconomic position, i.e. income, social prestige and education, had little impact on the odds ratios (ORs) for individual components. Following collective adjustment for the aforementioned covariates, a significant inverse relationship between IQ and high BMI, high triglycerides and low HDL-cholesterol (emerging for the first time) was apparent. When the metabolic syndrome was the endpoint of interest, higher IQ scores were associated with a reduced prevalence of this condition $\left(\mathrm{OR}_{1}\right.$ SD increase in IQ $0.86,95 \%$ CI $\left.0.80-0.99\right)$. Individual control for study covariates, including education, weakened this gradient very little. After full adjustment for all covariates, the OR was essentially the same as the analysis adjusted only for age and statistical significance was retained. When we related IQ to naturally coded (continuous) versions of each component that comprises the metabolic syndrome and to a PCA-derived index based on each of the components, the pattern of association of IQ with individual components was similar to that in Table 2 when each of the components was dichotomised. Thus, ageadjusted correlation coefficients were: $-0.067(p<0.001)$ for systolic blood pressure; $-0.077 \quad(p<0.001)$ for diastolic blood pressure; $-0.071(p<0.001)$ for BMI; $-0.038(p<$ $0.05)$ for triglycerides; $-0.021(p>0.05)$ for HDL-cholesterol; $-0.092(p<0.001)$ for blood glucose; and $-0.102(p<$ 0.001 ) for the factor-derived metabolic syndrome index (results for other adjustments available on request).

Figure 1 shows the results of the structural equation model used to explore the possible mediating effect of educational attainment between IQ and the metabolic syndrome. We present a number of different recommended fit indices so that the adequacy of the model can be assessed comprehensively [28, 29]. The measurement parts of the model were successful; the two indicators of mental ability loaded very highly on the latent trait of cognitive ability, and all indicators of the metabolic syndrome loaded significantly on the latent trait. The overall fit of the model was good. The average of the off-diagonal absolute standardised residuals was 0.03 . This indicates that the model accounted for most of the covariance among the measured variables. The root mean square error of approximation was 0.06 (95\% CI $0.055-0.066$ ), with good fit indicated by an upper bound of the $95 \%$ CI of less than 0.1 . The $\chi^{2}$ test value was large $(388.1, d f=23)$ and significant $(p<0.0001)$, but this is common in large samples. The Bentler-Bonett normed and non-normed and comparative fit indices were all good $(>0.9)$ at $0.95,0.92$ and 0.95 , respectively. These

Table 2 IQ and study characteristics in the Vietnam Experience Study $(n=4,157)$

\begin{tabular}{|c|c|c|}
\hline & $n(\%)$ & $\begin{array}{l}\text { IQ score }{ }^{\mathrm{b}} \\
\text { mean }(\mathrm{SD})\end{array}$ \\
\hline \multicolumn{3}{|l|}{ Data recorded at baseline } \\
\hline \multicolumn{3}{|l|}{ Age group (years) } \\
\hline$\leq 18$ & $584(14.0)$ & $98.1(13.1)$ \\
\hline $19-22$ & $3,192(76.8)$ & $101.3(15.1)$ \\
\hline$\geq 23$ & $381(9.2)$ & $106.3(17.6)$ \\
\hline \multicolumn{3}{|c|}{ Army income (US\$ per week) } \\
\hline $83-119$ & $513(12.3)$ & $93.6(13.8)$ \\
\hline $120-144$ & $2,059(49.5)$ & $99.1(15.1)$ \\
\hline 145 & $1,585(38.1)$ & $106.7(13.9)$ \\
\hline \multicolumn{3}{|l|}{ Place of service } \\
\hline Ever served in Vietnam & $2,299(55.3)$ & $100.4(14.8)$ \\
\hline Other overseas posting & $1,069(25.7)$ & $101.6(15.7)$ \\
\hline Served in USA only & $789(19.0)$ & $103.8(15.5)$ \\
\hline \multicolumn{3}{|l|}{ Ethnic group } \\
\hline White & $3,405(81.9)$ & $103.9(14.2)$ \\
\hline Black & $492(11.8)$ & $87.7(13.2)$ \\
\hline Other $^{\mathrm{a}}$ & $261(6.3)$ & $93.6(14.5)$ \\
\hline \multicolumn{3}{|l|}{ Data recorded at follow-up } \\
\hline \multicolumn{3}{|l|}{ Educational attainment } \\
\hline Grade $\leq 11$ & $502(12.1)$ & $86.6(12.1)$ \\
\hline Grade 12 & $1,515(36.4)$ & $97.0(12.8)$ \\
\hline Grade $\geq 13$ & $2,140(51.5)$ & $107.9(13.9)$ \\
\hline \multicolumn{3}{|c|}{ Family income (US\$ per year) } \\
\hline$\leq 20,000$ & $1,195(28.7)$ & $94.1(14.7)$ \\
\hline $20,001-40,000$ & $2,065(49.7)$ & $101.7(14.0)$ \\
\hline$>40,000$ & $897(21.6)$ & $110.2(13.4)$ \\
\hline \multicolumn{3}{|l|}{ Occupational prestige } \\
\hline$\leq 25$ th percentile & $1,132(27.2)$ & $94.1(14.4)$ \\
\hline 26th-50th percentile & $961(23.1)$ & $97.2(13.8)$ \\
\hline 51st-75th percentile & $1,313(31.6)$ & $104.8(13.7)$ \\
\hline$>75$ th percentile & $751(18.1)$ & $111.5(12.8)$ \\
\hline
\end{tabular}

${ }^{\text {a }}$ Comprises Hispanics, Asians, Pacific Islanders, American Indians and Alaskan Natives

${ }^{\mathrm{b}} p<0.001$ for all comparisons 


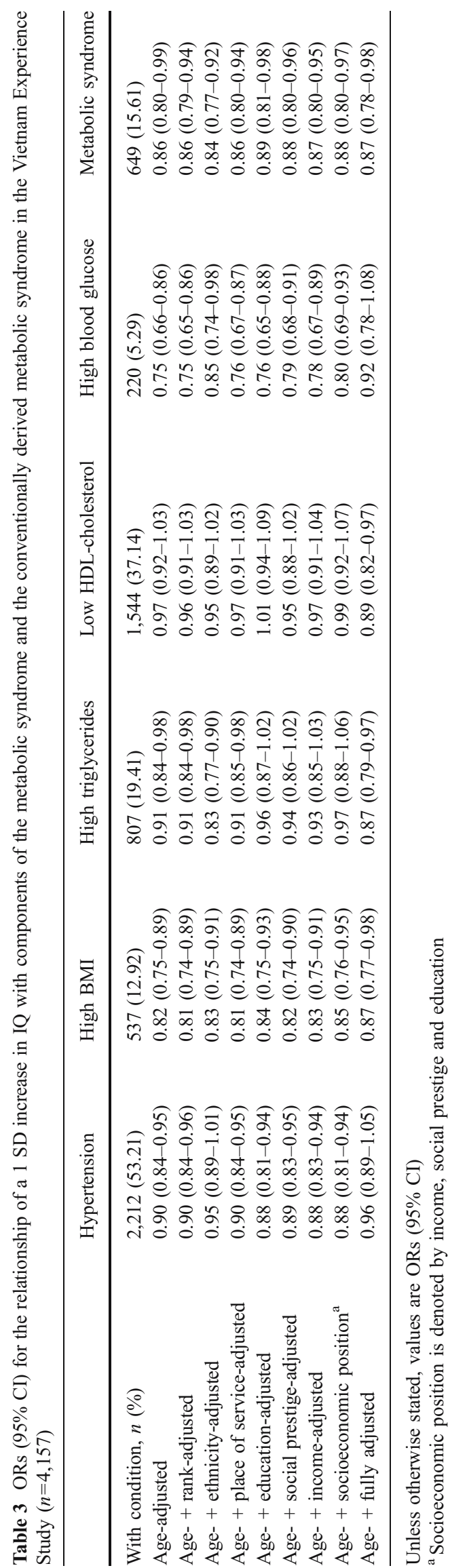
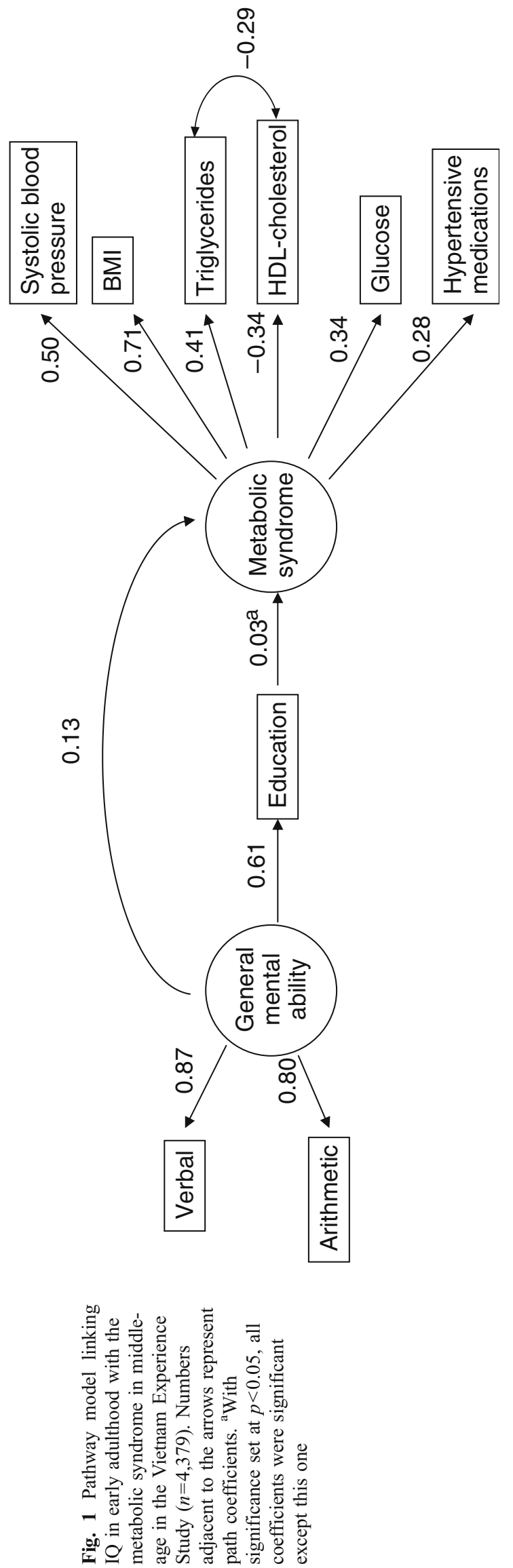
indices compare the stipulated model with a baseline model (in which the variables are uncorrelated) and have a maximum value of 1 . The path weight of the association between general mental ability and the metabolic syndrome latent trait was $0.13(p<0.01)$. These path weights may be considered as being similar to standardised partial beta weights in a regression model; if squared, they give the variance shared by adjacent variables in the model. As anticipated, general mental ability was highly related to education (path weight 0.61 ). In the path model, there was only a weak and statistically non-significant association between education and the metabolic syndrome latent trait (path weight $0.03, p>0.05$ ); therefore, education did not act as a significant mediator of the association between early adult mental ability and the metabolic syndrome.

Finally, as shown in Table 4, we examined the impact of controlling for the metabolic syndrome on the relationship between IQ and both total and CVD mortality. Some mediating impact was anticipated, given the previously described relationship between IQ and the metabolic syndrome, and the finding that the metabolic syndrome, as expected, was associated with all-cause mortality in this cohort. Thus in age-adjusted analyses, both the conventionally derived metabolic syndrome $\left(\mathrm{HR}_{\geq 3}\right.$ components vs fewer $1.98,95 \%$ CI 1.48-2.65) and the PCA-derived version $\left(\mathrm{HR}_{1}\right.$ SD increase $1.35,95 \%$ CI $\left.1.21-1.51\right)$ predicted total mortality risk. However, the age-adjusted relationship between high IQ and total mortality $\left(\mathrm{HR}_{1} \mathrm{SD}\right.$ increase in IQ 0.70 , $95 \%$ CI $0.61-0.79)$ was little changed when the conven- tionally derived index $\left(\mathrm{HR}_{1} \mathrm{SD}\right.$ increase in IQ $0.72,95 \% \mathrm{CI}$ $0.63-0.81)$ and the PCA-derived index ( $\mathrm{HR}_{1} \mathrm{SD}$ increase in IQ $0.73,95 \%$ CI $0.64-0.82$ ) were separately added to the multivariable model. The change in comparison to ageadjusted HRs was $\leq 10 \%$. Controlling for markers of socioeconomic position and education, particularly in middle-age, yielded by far the greatest attenuation in the strength of the IQ-mortality relationship (70\%). When CVD was the outcome of interest, adding the conventionally derived metabolic syndrome $\left(\mathrm{HR}_{1} \mathrm{SD}\right.$ increase in IQ $0.78,95 \%$ CI 0.61-1.00) and, particularly, the PCA-derived index $\left(\mathrm{HR}_{1}\right.$ SD increase in IQ $0.83,95 \%$ CI $\left.0.65-1.06\right)$ to the multivariable model had a larger impact on its relationship with IQ than in the analyses in which total mortality was the endpoint; statistical significance was lost at conventional levels. Again, controlling for later life socioeconomic position led to the greatest attenuation (92\%) of any of the covariates $\left(\mathrm{HR}_{1} \mathrm{SD}\right.$ increase in IQ $\left.0.98,95 \% \mathrm{CI} 0.72-1.32\right)$.

\section{Discussion}

To our knowledge, this is the first study to examine the link between IQ and the metabolic syndrome, and to assess the impact, if any, of controlling for the metabolic syndrome on the IQ-mortality gradient. We found that men with higher IQ test scores in early adulthood experienced a reduced prevalence of the metabolic syndrome in middle-age. This gradient was not explained by control for markers of

Table 4 HRs $(95 \%$ CI) for the relationship of a 1 SD increase in IQ with total and cardiovascular disease mortality in the Vietnam Experience Study

\begin{tabular}{|c|c|c|c|c|}
\hline & \multicolumn{2}{|l|}{ Total mortality ${ }^{\mathrm{a}}$} & \multicolumn{2}{|l|}{ CVD mortality } \\
\hline & HR $(95 \% \mathrm{CI})$ & $\begin{array}{l}\text { Per cent reduction } \\
\text { in } \mathrm{HR}^{\mathrm{d}}\end{array}$ & HR $(95 \%$ CI $)$ & $\begin{array}{l}\text { Per cent reduction } \\
\text { in } \mathrm{HR}^{\mathrm{d}}\end{array}$ \\
\hline Age-adjusted & $0.70(0.61-0.79)$ & - & $0.75(0.59-0.96)$ & - \\
\hline $\begin{array}{l}\text { Age- + ethnicity-, place of service-, army } \\
\text { income-adjusted }\end{array}$ & $0.83(0.81-1.09)$ & 43.3 & $0.86(0.65-1.13)$ & 44.0 \\
\hline Age- + systolic blood pressure-adjusted & $0.71(0.63-0.81)$ & 3.3 & $0.77(0.61-0.98)$ & 8.0 \\
\hline Age- + BMI-adjusted & $0.71(0.63-0.81)$ & 3.3 & $0.79(0.62-1.01)$ & 16.0 \\
\hline Age- + blood glucose-adjusted & $0.73(0.64-0.83)$ & 10.0 & $0.81(0.63-1.03)$ & 24.0 \\
\hline Age- + HDL-cholesterol-adjusted & $0.71(0.62-0.81)$ & 3.3 & $0.76(0.60-0.98)$ & 4.0 \\
\hline Age- + triglycerides-adjusted & $0.71(0.62-0.81)$ & 3.3 & $0.78(0.61-0.99)$ & 12.0 \\
\hline $\begin{array}{l}\text { Age- }+ \text { adult socioeconomic position }{ }^{\mathrm{c}} \text {-adjusted } \\
\text { Metabolic syndrome: }\end{array}$ & $0.91(0.78-1.06)$ & 70.0 & $0.98(0.72-1.32)$ & 92.0 \\
\hline Age- + conventionally derived-adjusted & $0.72(0.63-0.81)$ & 6.7 & $0.78(0.61-1.00)$ & 12.0 \\
\hline Age- + PCA-derived-adjusted & $0.73(0.64-0.82)$ & 10.0 & $0.83(0.65-1.06)$ & 32.0 \\
\hline
\end{tabular}


socioeconomic circumstances either at the time of IQ testing (army income) or during measurement of the components of the metabolic syndrome (income, occupation, education). We did not find evidence that the IQmetabolic syndrome association is mediated by education. Controlling for the metabolic syndrome had little impact on the IQ-total mortality relationship, with greater attenuation seen for IQ-CVD. This might be ascribed to CVD being more strongly linked with the metabolic syndrome than allcause mortality [30], the latter comprising a range of outcomes that will dilute the strength of the association.

Plausible mechanisms As described, early life IQ is associated with more favourable levels of smoking [2-5], physical exertion [6], dietary characteristics $[6,7]$ and heavy alcohol consumption [31], although the latter is not a universal finding [32-34]. This suggests that the skills captured by IQ tests, such as verbal comprehension and reasoning, may be important in the successful management of a person's health behaviours. As such, it is perhaps unsurprising that IQ is also associated with several physiological correlates of these behaviours, e.g. blood pressure, adiposity, blood glucose and cholesterol, which collectively represent the metabolic syndrome.

Study strengths and limitations This study has a number of strengths, not least its prospective design and the temporal measurement of IQ, which preceded that of the metabolic syndrome and, in turn, mortality. Moreover, we used an appropriate combination of epidemiological and structural equation models to fully understand the associations and possible confounding and mediating factors. Having IQ test scores from late adolescence or early adulthood, rather than from older ages, is also crucial in examining the link between cognitive ability and the metabolic syndrome. Where mental test data are available from earlier in life, any apparent protective effect of high IQ scores is unlikely to be explained by reverse causality, in which components of the metabolic syndrome themselves could actually lead to a reduction in cognitive function [35].

The study is limited in that women were not examined. It is uncertain to what extent these results might be applicable to women. Second, the range of IQ scores in the present cohort may be narrower than in general population groups, not only due to the occupational nature of the population studied (the so called 'healthy worker' effect), but also because, from the outset, personnel with a rank corresponding to above sergeant were excluded from the study sample. However, any reduced variance would lead to an underestimation of the true effect of IQ on the metabolic syndrome. Third, to our knowledge, the original IQ tests were in the English language, which may have handicapped ethnic minorities.
In conclusion, in this first study to examine the link between IQ and the metabolic syndrome, we found an inverse relationship, which was not mediated by education. The metabolic syndrome did not, however, appear to substantially mediate the relationship between high IQ scores and lower mortality rates, although some attenuation was apparent when CVD death was the endpoint of interest.

Acknowledgements G. D. Batty is a Wellcome Trust Fellow; M. Shipley is supported by the British Heart Foundation; I. J. Deary is the recipient of a Royal Society-Wolfson Research Merit Award.

Duality of interest The authors declare that there is no duality of interest associated with this manuscript.

\section{References}

1. Batty GD, Deary IJ, Gottfredson LS (2007) Premorbid (early life) IQ and later mortality risk: systematic review. Ann Epidemiol $17: 278-288$

2. Batty GD, Deary IJ, MacIntyre S (2007) Childhood IQ in relation to risk factors for premature mortality in middle-aged persons: the Aberdeen Children of the 1950s Study. J Epidemiol Community Health 61:241-247

3. Batty GD, Deary IJ, Schoon I, Gale C (2006) Mental ability across childhood in relation to risk factors for premature mortality in adult life: the 1970 British Cohort Study. J Epidemiol Community Health 60:872-874

4. Batty GD, Gale CR, Chandola T, Deary IJ (2007) Early life IQ, risk factors, and later cardiovascular disease: new data from the 1958 British Birth Cohort and a systematic review. In: Alves JG, Sampaio-Carneiro M (eds) Prevention of adult chronic diseases in infancy and adolescence (in Brazilian Portuguese). Medbook, Rio de Janeiro, pp 29-46

5. Taylor MD, Hart CL, Davey Smith G et al (2003) Childhood mental ability and smoking cessation in adulthood: prospective observational study linking the Scottish Mental Survey 1932 and the Midspan Studies. J Epidemiol Community Health 57:464-465

6. Batty GD, Deary IJ, Schoon I, Gale CR (2007) Childhood mental ability in relation to food intake and physical activity in adulthood: the 1970 British Cohort Study. Pediatrics 119:e38-e45

7. Gale CR, Deary IJ, Schoon I, Batty GD (2007) IQ in childhood and vegetarianism in adulthood: 1970 British Cohort Study. BMJ $334: 245$

8. Starr JM, Taylor MD, Hart CL et al (2004) Childhood mental ability and blood pressure at midlife: linking the Scottish Mental Survey 1932 and the Midspan Studies. J Hypertens 22:893-897

9. Lindgarde F, Furu M, Ljung BO (1987) A longitudinal study on the significance of environmental and individual factors associated with the development of essential hypertension. J Epidemiol Community Health 41:220-226

10. Chandola T, Deary IJ, Blane D, Batty GD (2006) Childhood IQ in relation to obesity and weight gain in adult life: the National Child Development (1958) Study. Int J Obes (Lond) 30:1422-1432

11. Sorensen TI, Sonne-Holm S, Christensen U (1983) Cognitive deficiency in obesity independent of social origin. Lancet 1:1105-1106

12. Teasdale TW, Sorensen TI, Stunkard AJ (1992) Intelligence and educational level in relation to body mass index of adult males. Hum Biol 64:99-106

13. Hart CL, Taylor MD, Davey Smith G et al (2004) Childhood IQ and cardiovascular disease in adulthood: prospective observational 
study linking the Scottish Mental Survey 1932 and the Midspan Studies. Soc Sci Med 59:2131-2138

14. The Centers for Disease Control Vietnam Experience Study (2004) Postservice mortality among Vietnam veterans. JAMA 257:790-795

15. Boehmer TK, Flanders WD, McGeehin MA, Boyle C, Barrett DH (2004) Postservice mortality in Vietnam veterans: 30-year followup. Arch Intern Med 164:1908-1916

16. Batty GD, Shipley MJ, Mortensen L et al (2008) IQ in late adolescence/early adulthood, risk factors in middle-age, and later all-cause mortality in men: the Vietnam Experience Study. J Epidemiol Community Health (in press)

17. Duncan O (1961) A socioeconomic index for all occupations. Free Press, New York

18. Stevens G, Cho J (1985) Socioeconomic indexes and the new 1980 Census Occupational Classification Scheme. Soc Sci Res $14: 142-168$

19. The Centers for Disease Control Vietnam Experience Study (1988) Health status of Vietnam veterans. I. Psychosocial characteristics. JAMA 259:2701-2707

20. The Centers for Disease Control Vietnam Experience Study (1988) Health status of Vietnam veterans. II. Physical Health. JAMA 259:2708-2714

21. Expert Panel on Detection, Evaluation, and Treatment of High Blood Cholesterol in Adults (2001) Executive summary of the third report of The National Cholesterol Education Program (NCEP) Expert Panel on Detection, Evaluation, and Treatment of High Blood Cholesterol in Adults (Adult Treatment Panel III). JAMA 285:2486-2497

22. Alberti KG, Zimmet PZ (1998) Definition, diagnosis and classification of diabetes mellitus and its complications. Part 1: diagnosis and classification of diabetes mellitus provisional report of a WHO consultation. Diabet Med 15:539-553

23. Pladevall M, Singal B, Williams LK et al (2006) A single factor underlies the metabolic syndrome: a confirmatory factor analysis. Diabetes Care 29:113-122
24. Kline P (1994) An easy guide to factor analysis. Routledge, London

25. Bentler P (1995) EQS structural equations program manual. Multivariate Software, Encino

26. Deary IJ, Strand S, Smith P, Fernandes C (2007) Intelligence and educational achievement. Intelligence 35:13-21

27. Cox DR (1972) Regression models and life-tables. J R Stat Soc [Ser B] 34:187-220

28. Kline R (2005) Principles and practice of structural equation modeling. Guilford, New York

29. Bentler P (2007) On tests and indices for evaluating structural models. Pers Individ Differ 42:825-829

30. Ford ES (2005) Risks for all-cause mortality, cardiovascular disease, and diabetes associated with the metabolic syndrome: a summary of the evidence. Diabetes Care 28:1769-1778

31. Batty GD, Deary IJ, MacIntyre S (2006) Childhood IQ and life course socioeconomic position in relation to alcohol induced hangovers in adulthood: the Aberdeen Children of the 1950s Study. J Epidemiol Community Health 60:872-874

32. Mortensen LH, Sorensen TI, Gronbaek M (2005) Intelligence in relation to later beverage preference and alcohol intake. Addiction 100:1445-1452

33. Hatch SL, Jones PB, Kuh D et al (2007) Childhood cognitive ability and adult mental health in the British 1946 birth cohort. Soc Sci Med 64:2285-2296

34. Batty GD, Deary IJ, Schoon I et al (2008) Childhood mental ability in relation to alcohol drinking problems and consumption in adulthood: the 1970 British Cohort Study. Am J Public Health (in press)

35. MacLullich AM, Deary IJ, Starr JM, Walker BR, Secki JR (2004) Glycosylated hemoglobin levels in healthy elderly nondiabetic men are negatively associated with verbal memory. J Am Geriatr Soc 52:848-849

36. Batty GD, Der G, MacIntyre S, Deary IJ (2006) Does IQ explain socioeconomic inequalities in health? Evidence from a population based cohort study in the west of Scotland. BMJ 332:580-584 